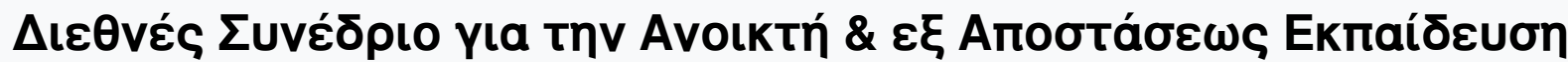

Tón. 8, Ap. 4B (2015)

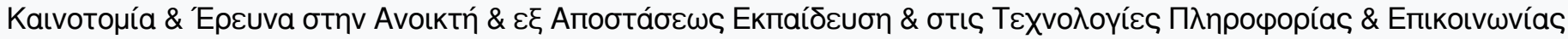

| ПракüKá

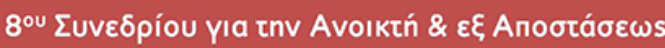

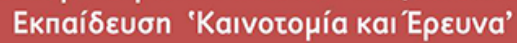

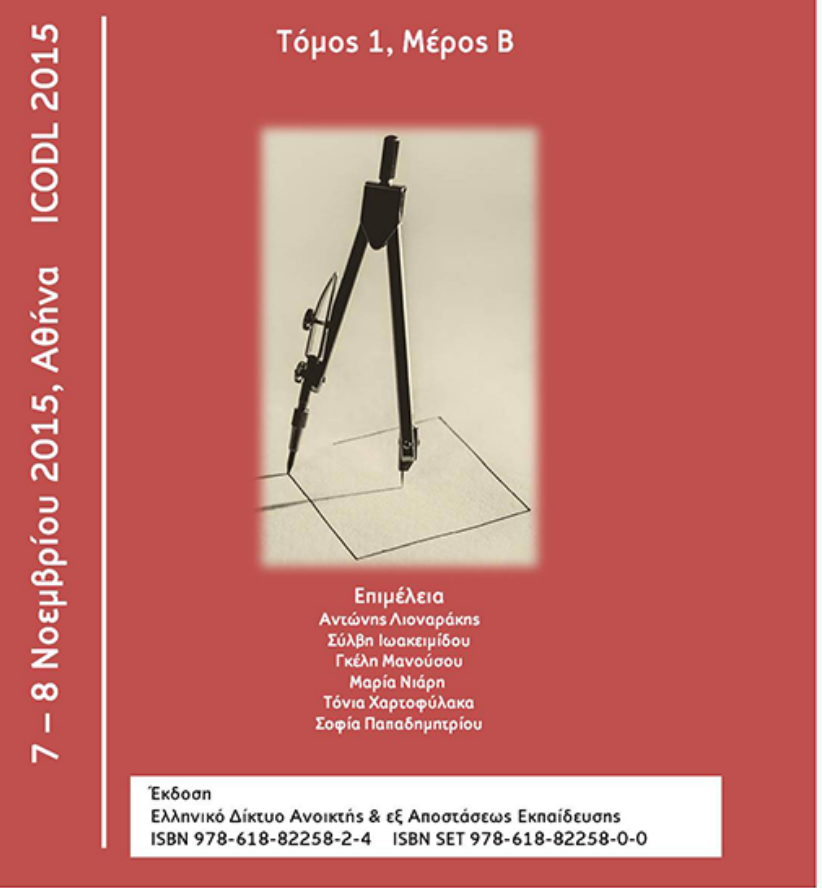

Mobile Blended Learning with eSquirrel

Michael Maurer

doi: $10.12681 /$ icodl. 62 


\title{
Mobile Blended Learning with eSquirrel
}

\author{
Michael Maurer \\ eSquirrel e.U., CEO \\ $\underline{\text { michael@eSquirrel.at }}$
}

\begin{abstract}
This article outlines the state of the art of mobile blended learning apps. It describes recent progress in this area, and explains the potential of mobile blended learning for schools and educational institutions. Furthermore, it presents an innovative solution, eSquirrel, which is developed by an Austrian inter-disciplinary start-up. eSquirrel is a blended learning platform that combines mobile learning with gamification. It blends the concepts of classroom teaching, eLearning and learning from books into a native Android and iOS course app, and enables teachers to learn their students' progress.
\end{abstract}

Key-words: mobile learning, blended learning, gamification

\section{Introduction}

Even though a lot of IT-aided learning has been developed in the last decades, there is still a lot of potential uncovered in how new technologies such as state-of-the-art smartphones or tablets can be used to leverage learning processes. We find three of the key possibilities of efficient IT-aided learning are:

(i) the empowerment of students to learn at their own pace;

(ii) teachers (or IT systems) that know what a student actually knows and at what time to provide help for what they do not know.

(iii) mechanisms that help students retain knowledge and competences in the long run. The first two aspects are crucial for diversification in a heterogeneous class, and aspect (iii) is especially important for schools with school leaving exams at the end of 4 or 5 year school form. Currently, no IT system tackles these aspects in a satisfying way.

This paper presents and compares concepts to satisfy the three mentioned aspects and presents an implementation of these concepts. The concepts comprise blended learning, which combines eLearning with classroom face to face learning, and mobile learning, which represents learning "on the go" on smartphones any time, any where. Thirdly, the concept of gamification is the idea of bringing gaming elements into a typically non-gaming environment, such as schools or learning. Gamification uses these gaming elements to motivate students to achieve certain learning goals.

The remainder of this paper is organized as follows: Section 2 discusses related eLearning approaches and compares eLearning with blended learning applications. Section 3 focuses on the rather new element of mobile learning. Section 4 describes eSquirrel, which implements concepts mentioned in the previous sections. Section 5 suggests an evaluation scenario of eSquirrel, and Section 6 concludes the paper. 


\section{Related work}

\section{eLearning vs Blended Learning}

Recently, many apps for eLearning have emerged. Generally, they can be divided into two groups: Firstly, apps that enable "only" eLearning. These apps try to teach new content to students, e.g., Duolingo (2015) or Babbel (2015) for languages. Whereas these apps may offer social functions, e.g., displaying friends who use the same app, this is not their primary purpose. Their primary purpose is to enable the learner to learn new content on their own without the help of an external supervisor or teacher.

The second group of apps includes the non-virtual perspective of learning, the so called "Blended Learning apps". E.g., Socrative (2015) can be used to present and evaluate short quizzes during class. Teachers put quizzes online, while students answer these quizzes on their mobile phone app. The teacher then instantaneously sees statistics of all the answers and can project them on screen. Socrative can not only be used for testing, but also for asking for opinions (polling) in debates. The blended learning platform Kahoot! (2015) uses a similar concept. Other blended learning tools such as Edmodo (2015) or Otus (2015) help teachers to provide students with resources and tests. In Otus, e.g., students can take notes with the app directly in class.

Experiencing blended learning, the social ties between teachers and students, and between students among themselves, play an important role. Students find themselves in a competitive situation. The learning pressure is increased, as internet anonymity or the distance towards a computer program disappears. Authors as Arnold (2010) or Hoeksema (2008) see this fact as the crucial advantage of blended over eLearning.

\section{Apps that teach and apps that train}

As an additional aspect, apps can be divided into apps that focus on explaining content and those that focus on training content. Brainscape (2015), AnkiDroid (2015) or Memrise (2015) train knowledge by translating the analogue method of Flashcards into a mobile app. Memrise (2015) even includes the concept of spaced repetitions, i.e., repeating unfamiliar pieces of knowledge more often than familiar ones.

Apps that explain content are for example Duolingo (2015) or Babbel (2015). An example summarizing this two-dimensional taxonomy is presented in Table 1.

\begin{tabular}{|l|l|l|}
\hline \multicolumn{1}{|c|}{ eLearning } & Blended Learning \\
\hline $\begin{array}{l}\text { Teach new } \\
\text { content }\end{array}$ & Duolingo, Babbel & Socrative, Kahoot!, Edmodo, Otus \\
\hline Train content & $\begin{array}{l}\text { Brainscape, Memrise, } \\
\text { Ankidroid }\end{array}$ & eSquirrel \\
\hline
\end{tabular}

Table 1: Taxonomy of mobile learning apps

\section{Mobile learning}

Mobile learning on smartphones brings a new dimension into eLearning and Blended learning. Learning does no longer have to be bound to a desk or a classroom. Learning via smartphones takes place everywhere: in trains, when waiting for the metro, or in coffee shops. These new learning possibilities also change learning behavior. Learning phases become shorter, but can occur more often. Thus, the content presented in smartphone apps has to be arranged accordingly.

Apps that train content have to present the exercises in a more concise way so that they fit on a smartphone screen. As a consequence, many of these small exercises - 
sometimes referred to as "knowledge bites" or "eTapas" (2015) - should exist and they should vary in their style, e.g., by presenting content in different question formats.

Moreover, the mobile exercises may profit from the haptics of the smartphone. In this way, students can not only think the exercise, but also "feel" it, e.g., by moving items with their fingers to put them into correct places.

To the best of the author's knowledge there is no high-quality platform that combines blended learning, the long-term training of competencies and mobile learning.

\section{4. $\quad$ Long-term mobile blended learning using eSquirrel}

The blended learning platform eSquirrel bridges the gap above and offers teachers the possibility to easily design a mobile course tailored to their teaching. Students download these courses via their smartphones and can then use them in a native Android or iOS app even off-line. Teachers see the progress of their students in the teacher's portal.

\section{Creating a course via the author's web tool}

The course can be based on the teacher's own course materials or school book chapters. The course is divided into chapters and learning units, so called quests, which themselves consist of short questions. The whole course resembles the book in colors and structure such that students acquainted to the book or learning materials can easily navigate in the app course. So far, there exist eight different question types, such as multiple choice questions, elimination questions, i.e., wrong answers have to be eliminated, clozes, or pairing questions, i.e., correct pairs have to be matched. Questions can include pictures and also render mathematical formulae, when they are set using an online LaTex editor.

\section{Learning via the student's Android and iOS app}

The student's app trains knowledge and competences targeted for long-term memory. It achieves this using elements of gamification (Kapp, 2014) and spaced repetitions, cf. Section 2. The course resembles a game that consists of different quests grouped into chapters. A quest is considered as completed for students when the quest is repeated three times within different time intervals. The game can be "won" by completing all quests. Additionally, it can be measured how well it was won by measuring the number of questions answered correctly in quests. This means that students are rewarded in a dual way: for repeating an entire quest in a timely fashion and for correctly answering questions in these quests.

The content of the course in the app and its game-like character are automatically generated by eSquirrel. The teacher is only responsible for creating the content of the course. eSquirrel provides the gamification thereof.

\section{Analyzing students' progress via the teacher's web portal}

Via the teacher's web portal, teachers can see and analyze their students' progress. They see what their students know, even before they enter the classroom. Not only do they see which chapters and quests the students already completed, but they also learn statistical data. These statistics include questions that students answered correctly the first time, so called easy questions, or difficult questions that many students answered wrongly. The statistics also show which questions were remembered correctly over the long run. Thus, the teacher's portal gives insight into what students know and what they do not know, but also what competences they understand easily and which 
they struggle with. Consequently, teachers can better prepare their lessons with real time learning data and better approach students' needs.

\section{Benefit Hypothesis when using eSquirrel}

According to the author's mind, the strength of eSquirrel lies in the combination of eLearning and non-virtual learning, and the separation of teaching knowledge and training knowledge. With the assumption that a good app cannot replace a good teacher or a good book, the hypothesis is that combining these two (app, teacher) or three elements (app, teacher, book) - teachers and books that teach, and apps that train - achieves a learning quality that cannot be reached via regular classroom teaching. More specifically, eSquirrel's next step is to test the efficiency of learning with and without eSquirrel.

A setup to evaluate eSquirrel consists of teachers who teach (at least) two classes at the same school and at the same educational level, where one class uses eSquirrel, and the other does not. After using eSquirrel for a term, the evolvement of the grades of both classes is compared with the performance of the class in the previous term.

\section{Conclusion}

The concepts of mobile and blended learning empower the student to learn at his own pace ubiquitously and give teachers the chance to know what their students know, even before they enter the classroom.

In this paper we have examined several eLearning mobile apps. Comparing eLearning and blended learning systems we found that eSquirrel is the first current implementation of a mobile app that trains knowledge in the long term and gives teachers instantaneous feedback about their students' progress.

The team of eSquirrel currently works on the implementation of their blended learning app and constantly improves their release candidate. Next steps are the addition of additional features, such as social functions for students, and the evaluation of the eSquirrel platform in a field experiment.

\section{Bibliographic References:}

Ankisrs.net. (2015). Anki - powerful, intelligent flashcards. Retrieved 24 October 2015, from http://ankisrs.net/

Babbel.com. (2015). Lerne Englisch, Spanisch und andere Sprachen online - Babbel.com. Retrieved 24 October 2015, from http://de.babbel.com

Brainscape.com. (2015). Brainscape | Find, Create, \& Study Smart Flashcards $\mid$ Brainscape. Retrieved 24 October 2015, from http://www.brainscape.com

Duolingo.com. (2015). Duolingo | Learn Spanish, French, German, Portuguese, Italian and English for free. Retrieved 24 October 2015, from http://www.duolingo.com

Edmodo.com. (2015). Connect With Students and Parents in Your Paperless Classroom | Edmodo. Retrieved 24 October 2015, from http://www.edmodo.com

Elc20.com. (2015). eLC 2.0: eTapas Infos. Retrieved 24 October 2015, from http://elc20.com/index.php?id=33

Hoeksema, K., \& Kuhn, M. (2008). Unterrichten mit Moodle. München: Open Source Press.

Kahoot.it. (2015). Kahoot!. Retrieved 24 October 2015, from http://www.kahoot.it

Kapp, K., Blair, L., \& Mesch, R. The gamification of learning and instruction fieldbook.

Memrise. (2015). Memrise - Learn something new every day. Retrieved 24 October 2015, from http://www.memrise.com

Otus Plus. (2015). Otus - Otus Plus. Retrieved 24 October 2015, from http://www.otusplus.com

Rolf, A., Nolda, S., \& Nuissl, E. (2010). Wörterbuch Erwachsenenbildung (2nd ed.). Julius Klinghardt.

Socrative.com. (2015). Socrative. Retrieved 24 October 2015, from http://www.socrative.com 